\title{
Collective Efficacy and its Relationship with Leadership in a Computer-mediated Project-based Group Work
}

\author{
Yeol Huh, Charles M. Reigeluth, \& Dabae Lee \\ Indiana University, United States
}

\begin{abstract}
Based on Bandura's work, the four sources of efficacy shaping were examined in regard to frequency and students' perception of importance in a computer-mediated, project-based high school classroom. In a context of group work where there was no designated leader, groups' collective efficacy was examined if it has any relationship with individual's leadership traits. In addition, the relationship between the existence of group-identified leader and the groups' collective efficacy as well as the relationship between the collective efficacy and the groups' performance outcome were examined. The results from survey and interview showed that mastery experience was the most frequent and powerful source of efficacy shaping among the four sources. Moreover, the groups with identified leader showed higher collective efficacy than the groups without leaders, and the groups' collective efficacy level showed positive correlation with the groups' performance outcome.
\end{abstract}

Keywords: Collective efficacy; Leadership traits; Computer-based PBL; Group performance

\section{Introduction}

Since Bandura $(1977,1978)$ introduced the idea of self-efficacy, a line of research has been conducted regarding the relationship between self-efficacy and other factors such as selfregulation and performance in various disciplines (e.g. business, health, sports, and education). However, under circumstances that require any kind of group work or teamwork, self-efficacy is not enough to explain the performance of a team as a whole. For example, in a football team, a skilled quarterback may have a high level of self-efficacy, but other players' skill and efficacy levels need to be considered to determine the efficacy of the team (Bandura, 2000).

Later, the concept of collective efficacy was developed to explain more about the efficacy of a group or a team $(1977,1986)$. Moreover, in any discipline, especially current educational settings, there has been a growing need for and interest in collaboration in group work. In the field of education, collaboration is also considered by the Partnership for $21^{\text {st }}$ Century Skills (Partnership for 21st Century Skills, 2010) - an organization that consists of business and educational leaders as one of the $21^{\text {st }}$ century skills that students should have. Furthermore, Reigeluth, Watson, Watson, Dutta, Chen, and Powell (2008) also emphasized project-based learning as a major method in the Information-Age paradigm of education, one that typically depends on group work. With the increasing emphasis on group work, there is a greater need to further investigate 
collective efficacy. In this study, the sources that shape collective efficacy and the role of leadership in groups' collective efficacy, as well as the outstanding leadership traits of groupidentified leaders were examined.

\section{Review of Literature}

\section{Collective Efficacy}

Bandura defined perceived self-efficacy as a person's belief in his/her capability to organize and implement a series of actions to produce given attainments (Bandura, 1978, 1986; Riggs \& Knight, 1994; Wood \& Bandura, 1989). Later, given the holistic nature of a group, Bandura $(1977,1986)$ defined another concept called collective efficacy. He stated that "collective efficacy is rooted in self-efficacy" (p. 143). However, Bandura himself and the subsequent research examining the relationship between self-efficacy and collective efficacy suggested that self-efficacy and collective efficacy are related but distinct concepts (Jex \& Gudanowski, 1992; Parker, 1994; Riggs \& Knight, 1994). The most widely accepted definition is Bandura's, in which he defined collective efficacy as "a group's shared belief in its conjoint capabilities to organize and execute the courses of action required to produce given levels of attainments" (Bandura, 1977, p. 447). Collective efficacy can be used interchangeably with the term, team-efficacy (Lindsley, Brass, \& Thomas, 1995). Some studies have claimed that team-efficacy and collective efficacy are different terms due to their unit of focus (Gully, Incalcaterra, Joshi, \& Beaubien, 2002). For example, the unit of focus in teamefficacy is only a team, whereas in collective efficacy it can be a department, an organization, and even a nation. However, in this study, collective efficacy refers to the capability perception of a group or a team.

Collective efficacy, just like self-efficacy, is to be shaped by four major sources: mastery experience, vicarious experience, verbal persuasion, and affective state (Bandura, 1977, 1986; Goddard, Hoy, \& Hoy, 2004). A mastery experience, also known as enactive mastery, is considered to be the most powerful source of efficacy (Goddard et al., 2004), and the perception that past group-work experiences have been successful can contribute to building up efficacy in similar contexts in the future. Goddard (2001) also identified that mastery experience significantly influences schools' perceived efficacy in a positive direction. Vicarious experience refers to learning by observing someone else who is high performing. Vicarious experience is considered to be a less dependable source of efficacy development than direct evidence like experienced mastery because it relies on inferences from social comparison (Bandura, 1978). In general, when the model (person or team) performs well, efficacy tends to increase, whereas when the model performs poorly, efficacy often decreases. Moreover it is known that the effect of vicarious experience is maximized when the students see themselves similar to the model(s). Verbal persuasion refers to "receiving encouragement or specific performance feedback from a supervisor or a colleague" (Goddard et al., 2004, p. 6). It is widely used due to its ease and ready availability, and the strength of a verbal persuasion highly relies on the credibility, trustworthiness, and expertise of the persuader (Bandura, 1978, 1986; Goddard et al., 2004). Lastly, affective state, the level of anxiety or excitement, influences the level of efficacy perception, but there is little research on the impact of the affective state of a team on its collective efficacy. While there has been much research on the 
sources of self-efficacy, there has been relatively little research on the sources of collective efficacy or on which sources are more influential than others in developing collective efficacy.

In addition, research has revealed a positive relationship between the level of collective efficacy and group performance across various organizational settings such as corporate, education, sports, nursing, and military (Bandura, 2000; George \& Feltz, 1995; Gibson, 1999; Goddard, 2001; Zaccaro, Blair, Peterson, \& Zazanis, 1995). Moreover, two meta-analyses conducted from 67 and 69 empirical studies, respectively, on collective efficacy also revealed that there was a positive relationship between collective efficacy and group performance (Gully et al., 2002; Stajkovic, Lee, \& Nyberg, 2009). However, a majority of research on collective or team efficacy was conducted in a business setting, and as mentioned before there has been little empirical research on collective efficacy and group performance in educational settings. Goddard investigated teachers' collective efficacy in relation to the students' academic achievement (Goddard, 2001, 2003; Goddard et al., 2004), but little research exists investigating the collective efficacy of student groups and their performance in a classroom setting.

\section{Measuring Collective Efficacy}

Bandura stated "A group's attainments are the product not only of shared knowledge and skills of the different members, but also of the interactive, coordinative, and synergistic dynamics of their transactions" (Bandura, 2006, p. 316). Thus, perceived collective efficacy is not simply the sum of individual self-efficacy of a group, but an emergent group level trait (Bandura, 2000). To measure collective efficacy, two main approaches were suggested (Bandura, 2000, 2006; Goddard et al., 2004).

The first approach is to combine individual members' appraisals of their individual capabilities to execute a particular series of actions in a group, that is, to aggregate individual self-efficacy. The second approach is to accumulate each individual group member's perception of group capability as a whole. Within the two main methods of measuring collective efficacy, the latter approach is considered to be more appropriate in that it can measure interactive aspects of group operation. Moreover, the questions about self-capability of each member are more prone to have a large variability depending on the function of individual difference without capturing group capability (Bandura, 2000; Gibson, Randel, \& Earley, 2000; Goddard et al., 2004; Gully et al., 2002; Stajkovic et al., 2009). For instance, Goddard (2003) in his study of teachers' collective efficacy showed that individual perceptions of self-efficacy - the first method - varied less than $5 \%$ among groups whereas those of group-capability - the second method - showed more than $40 \%$ variance among groups.

Other than the two main methods, some researchers proposed another approach for measuring collective efficacy, which is to make group members have a discussion and reach a consensus on the group's efficacy together (Bandura, 1977; Gibson et al., 2000; Stajkovic et al., 2009). However, this approach has a high risk of social desirability bias that may weaken the validity of the assessment (Bandura, 1977, 2000, 2006; Goddard et al., 2004; Stajkovic et al., 2009). Specifically, if group members have a discussion to assess their ability, they tend to reach an inaccurate conclusion about their group's collective efficacy, estimating higher efficacy than is accurate 
because it is socially desirable not to blame other members' low ability for affecting the group's efficacy.

A meta-analysis of 69 empirical studies shows that $82 \%$ of the identified research utilized the assessment of aggregating individual perception of a group's capability (Stajkovic et al., 2009). Thus, in this study the second method, that is, to assess individual perception of a group's capability as a whole was utilized for measuring collective efficacy. The survey question for assessing collective efficacy looked like, "The group I work with has above average ability." instead of "I have above average ability in group work."

\section{Leadership}

Given the past research findings that collective efficacy has a positive relationship with group or team performance, it seems beneficial to further investigate variables affecting collective efficacy. However, research on collective efficacy has mainly focused on outcomes, and relatively little research has been conducted on how collective efficacy is affected by other variables (Chen \& Bliese, 2002; Walumbwa, Wang, Lawler, \& Shi, 2004). In some studies, leadership was proposed as a predictor of collective efficacy (Chen \& Bliese, 2002; Hoyt, Murphy, Halverson, \& Watson, 2003; Walumbwa et al., 2004).

Leadership can be defined as "a process whereby an individual influences a group of individuals to achieve a common goal" (Northouse, 2004, p. 3). Thus, a necessary condition for leadership to exist is group work involving more than one individual, and subsequently it is related to collective efficacy. Within research on leadership, several approaches have been utilized to examine leadership. For instance, transactional leadership and transformational leadership are two commonly used approaches in viewing leadership (Bass, 1990; Burns, 1978; Kirkpatrick \& Locke, 1991; Northouse, 2004; Stogdill, 1948, 1974). Both concepts were first established by Burns as transforming leadership and transactional leadership, and further elaborated by Bass as transformational leadership and transactional leadership. Transactional leadership focuses mainly on leader's contingent reward, and transformational leadership on leader's inspiration, intellectual stimulation, and individualized consideration (Bass, 1990).

Among these various approaches to assess or examine leadership, this study purposefully utilized the traits approach. The traits approach is one of the approaches to investigate leadership that focuses on identifying innate qualities and characteristics (Kirkpatrick \& Locke, 1991; Northouse, 2004; Stogdill, 1948, 1974). In fact, the traits approach was utilized because it fitted the particular setting of this study better than other approaches. The reason why the traits approach was utilized is that, unlike the majority of research conducted on leadership in which official or designated leaders were already present, this study was conducted in an educational setting in which there was no official or designated leader in the group. That means each student member was supposed to have equity in terms of authority, responsibility, and other rights in group work. Thus, the existence of a so-called leader could be latent or even non-existent. The traits approach that mainly focuses on a person's leadership traits seemed more appropriate for this study because there was no external condition to make a person play a leader's role and take necessary responsibility. 
The hypothesis underlying employing the traits approach is that group-identified leader(s) may show certain leadership traits in common compared to non-leaders, and groups with identified leader(s) may show higher levels of collective efficacy than groups without leader(s). Also, given the initial level of collective efficacy perceived by each individual before the project, the postsurvey result of the collective efficacy may show a difference based on the existence of groupidentified leader(s), which may subsequently influence the performance outcome of the groups. In addition, certain leadership traits may have a relationship with the ideal behaviors of leaders identified by interviews. Figure 1 illustrates the hypothesis and the possible relationships addressed in the research questions.

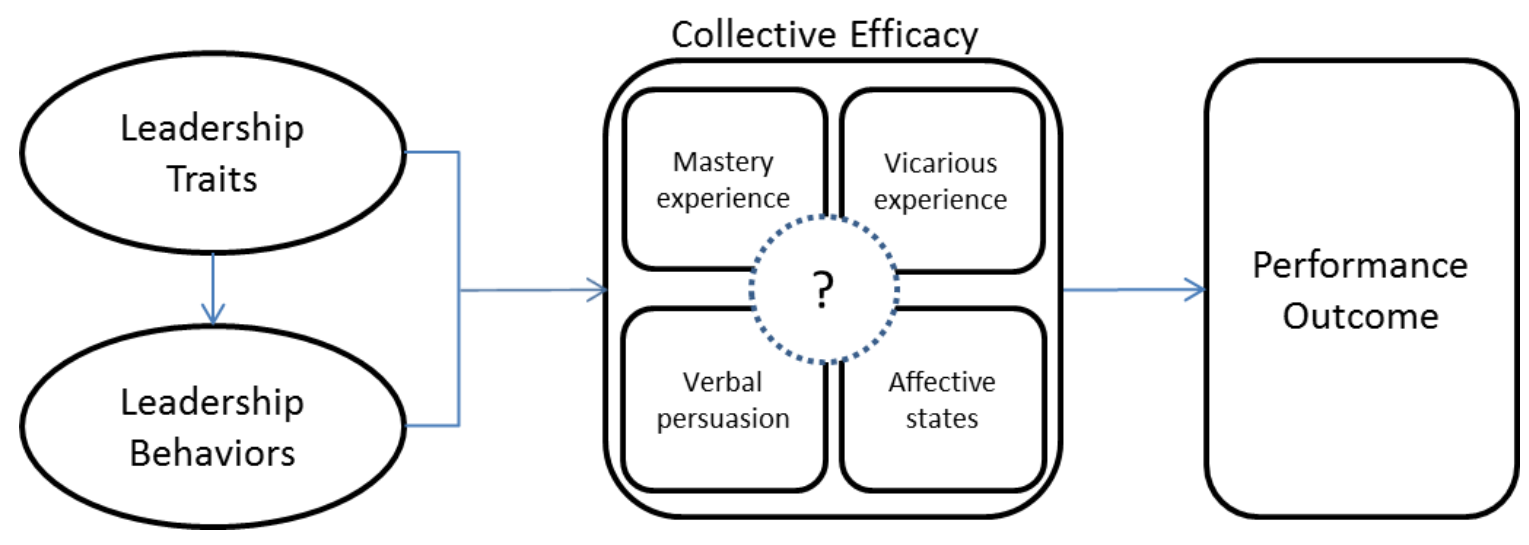

Figure 1. Leadership-Collective Efficacy Model

\section{Purpose of Study}

First, this study aims to investigate the elements that shape collective efficacy among high school students in a project-based learning context. In addition, the study examines the changes in collective efficacy level between the groups with an identified leader and the groups without an identified leader. The study further investigates what comprises the ideal leadership behaviors among the students. Finally, the study attempts to confirm if there is a positive relationship between each group's level of collective efficacy and the group's performance outcome.

In this regard, the study specifically seeks to answer the following research questions for group work in a computer-mediated, project-based educational setting:

\section{Sources of Efficacy Shaping}

A part of research questions are based on the sources of efficacy shaping.

- Which of the four sources of shaping collective efficacy (mastery experience, vicarious experience, verbal persuasion, and affective state) occur most frequently in group work? 
- Which of the four sources of efficacy shaping do the students perceive as most important in determining collective efficacy?

- If possible, what sources other than the four sources of efficacy shaping are found to build collective efficacy?

\section{Leadership and Collective Efficacy}

The other part of research questions is based on leadership traits and collective efficacy.

- Are there any differences in the level of groups' collective efficacy between groups with identified leader(s) and groups without identified leader(s)?

- Are there any outstanding leadership traits found in group-identified leader(s)?

- Does the level of collective efficacy of a group have any correlation with the performance outcome of the group?

\section{Methodology}

This study utilized a mixed methods research design, and a single naturalistic case study was conducted with surveys and interviews as data collection methods. The study was conducted in a natural classroom setting at one of the high schools in a small mid-western city in the United States. The study implemented a survey as the major method of data collection, and one-on-one interviews were also conducted to gather additional qualitative data.

\section{Setting and Participants}

The school where the study was conducted was slightly different from other traditional high schools in that all courses were based on projects. The school opened in fall 2008 with a class size of 96 students, and at the time of the study (fall 2010) it served students in grades 9 to 11 . Students were evaluated on the basis of eight learning outcomes (i.e., professional work ethic, local and global citizenship, collaboration, written communication, oral communication, critical thinking, technological literacy, and numeracy), most of which depict the $21^{\text {st }}$ century skills. Project-based learning is the major focus, and the school maintains a one-to-one studentcomputer ratio.

This research was specifically conducted in an American Studies classroom, which combined lessons for American history and English for mainly freshmen students. Two teachers co-teach the class, and they teach three sessions in a semester. There were 25, 25, and 29 students in the three sessions, respectively. Out of the 79 students in the three sections, 70 students participated in the pre-survey ( $89 \%$ response rate), 68 in the post-survey ( $86 \%$ response rate), and 16 students volunteered to participate in the interviews. In general, there were approximately 10 projects throughout one academic year, and each project lasted two to six weeks. Groups of three or four 
students generally worked on a project together. A total of 25 groups were examined in this study. The study was conducted on the project in which each group had to develop web pages regarding Martin Luther King Jr., and it lasted 5 weeks.

\section{Instruments}

A survey instrument was developed in four parts to assess (1) the frequency of each source of efficacy-shaping in their group-work experience, (2) the level of collective efficacy of each group, (3) students' perceptions of the importance of each efficacy-shaping source, and (4) individual leadership traits.

The first part of the survey was designed to assess the frequency of each of the four efficacyshaping elements from the students' past group-work experiences. A total of four questions were created based on the literature of Bandura $(2000,2006)$ and other researchers who suggested the four sources of efficacy shaping. Students' answers were gathered on a 7-point Likert scale.

The second part attempted to measure students' individual perceptions of their group's collective efficacy in general based on their past group-work experiences. The questions for measuring collective efficacy were adopted from Riggs and Knight's (1994) Collective Efficacy Beliefs Scale. There was a total of seven items using a 6-point Likert scale; however, the questions were changed to have a 7-point Likert scale, since a 7-point Likert scale could capture responses more accurately than a 5- or 6-point Likert scale (Groves et al., 2009). Also the original term 'my department' was modified to 'my group' to reveal the context accurately where they were doing group work, and the tense of the verbs were modified from present to past because the study attempted to measure collective efficacy in general based on the students' past group work experience. For example, the original question of "The department I work with has above ability" looked like "The group I worked with had above ability" or "Some members in this department cannot do their jobs well" looked like "Some members in the group could not do their jobs well." The modification on the scale was consulted with an expert who actually developed the original Collective Efficacy Beliefs Scale (i.e. M. L. Riggs) in order to obtain validity of the scale. In addition, the original seven items showed good internal consistency with Cronbach's alpha $=.88$ (Hoyt et al., 2003; Riggs, Warka, Babasa, Betancourt, \& Hooker, 1994), and the modified seven items also showed good internal consistency with Cronbach's alpha $=.805$ and .864 from the pre- and the post-surveys respectively.

The third part of the survey consisted of four items and was designed to assess students' perceptions of the importance of each efficacy-shaping element, and it is also based on a 7-point Likert scale.

The last part of the survey aimed to assess the students' self-appraisal of their own individual leadership traits. A set of questions to assess leadership traits was adopted from Northouse's (2004) Leadership Trait Questionnaire (LTQ), which contains 10 items. Although the original items have a 5-point Likert scale, it was also modified to a 7-point Likert scale to better capture the differences. 
In addition to the survey, a list of interview questions was developed for one-on-one interviews that followed the post survey. The interview questions were designed to examine whether there were additional sources of efficacy-shaping other than the four sources identified in the literature, and what kinds of behaviors they expected to see from an ideal leader. Examples of the interview questions were, "When you were asked to assess your group's capability, what kinds of things did you consider to form your decision?" and "What do you think the ideal leaders should look like?"

In this study, pre- and post-surveys were utilized. Even though pre- and post-surveys were implemented, this study was neither an experimental nor a quasi-experimental study, as it was conducted in a naturalistic classroom setting (Lincoln \& Guba, 1985). In addition, the level of collective efficacy assessed in pre- and post-surveys was not a result from a particular project, but a measure based on the students' past group-work experiences in general. Only in the post-survey, the students were asked whether there were any member(s) who showed more leadership than others, and who those member(s) were.

\section{Data Collection and Analysis}

The pre-survey was conducted after the students finished one project and before they started a new project. The new project lasted approximately five weeks, and the post-survey was conducted after the project ended. Also, one-on-one interviews were conducted upon completing the group project, and the final grade of each team project were provided by the teachers after the project ended.

The frequency of and the students' perception of importance on the sources of collective efficacyshaping were measured by simple descriptive statistics such as mean score of each of the four sources of efficacy-shaping, and the constructs that scored highest were identified. In addition, a One-Way Analysis of Variance (ANOVA) was conducted to identify if the mean differences among the four sources were statistically significant. The collective efficacy of each group was represented by group means, which were average scores from aggregating each member's level of collective efficacy. The leadership traits of each member were measured by self-report, and a ttest was conducted to examine whether there was any significant difference in any of the 10 leadership traits between the students who were identified as leaders and the students who were not. For the 10 leadership traits, an exploratory factor analysis (EFA) was also conducted to identify if the 10 traits could be explained by any factors. Moreover, an independent sample t-test was conducted to examine the differences among the means in the group's level of collective efficacy between the groups with an identified leader(s) and the groups without an identified leader(s). After the project ended, one-on-one interviews with volunteered group members were conducted to gather qualitative data about ideal leadership behaviors and to determine if there were any other sources of efficacy-shaping other than the four major sources (i.e. mastery experience, vicarious experience, verbal persuasion, and affective state). The interviews were conducted based on the four structured interview questions. All the interviews were audiorecorded and transcribed verbatim for further analysis. The transcriptions were coded using a coding sheet, and common themes were identified from the coding results. Lastly, the performance of each group was assessed by the final grade for the project given to each group by the teachers. 


\section{Findings}

Results are divided into three sections: sources of efficacy shaping and groups' collective efficacy and leadership. The first section covers research question 1 through 3 , and the second section covers question 4 through 7 . In the second section, the relationship between a group's collective efficacy and the existence of identified leader(s) in the group is described, along with data on any outstanding leadership traits identified among the leaders. In the third section, results of further analysis on types of leadership traits and successful group work are presented.

\section{Sources of Efficacy-Shaping}

In the first section, the frequency of each of the four sources of efficacy-shaping and the students' perceptions of importance of each source are examined from the pre and post surveys, and the themes from the interviews about additional sources of efficacy shaping are described.

\section{Research Question 1}

The students were asked how frequently they had experienced each efficacy-shaping source in their past group-work on both the pre- and post-surveys. The four sources listed were mastery experience, vicarious experience, verbal persuasion, and affective state. Table 1 shows the results of frequency-related questions. From their past group-work experiences, the students identified that they had experienced verbal persuasion from either teachers or other group members the most, followed by mastery experiences (which means successful past group-work experience). Affective state, either excited or nervous, showed less frequency compared to other sources of efficacy shaping. The mean differences between verbal persuasion and affective state as well as mastery experience and affective state were statistically significant.

Table 1. Frequency of Four Efficacy Shaping Sources in Group Work

\begin{tabular}{lcc}
\hline Source & Mean & Standard Deviation \\
\hline Verbal persuasion & 5.02 & 1.26 \\
Mastery experience & 4.82 & 1.04 \\
Vicarious experience & 4.59 & 1.51 \\
Affective state & 4.20 & 1.60 \\
\hline
\end{tabular}

(From 1 - never experienced to 7- always experienced)

\begin{tabular}{llcc}
\hline Source & & Mean Difference & Significance \\
\hline Mastery experience & Vicarious experience & .23 & .729 \\
& Verbal persuasion & -.20 & .811 \\
& Affective state & $.62^{*}$ & .029 \\
\hline Vicarious experience & Mastery experience & -.23 & .729 \\
& Verbal persuasion & -.43 & .221 \\
& Affective state & .39 & .302 \\
\hline
\end{tabular}




\begin{tabular}{llll}
\hline Verbal persuasion & Mastery experience & .20 & .811 \\
& Vicarious experience & .43 & .221 \\
& Affective state & $.82^{*}$ & .002 \\
\hline Affective state & Mastery experience & $-.62^{*}$ & .029 \\
& Vicarious experience & -.39 & .302 \\
& Verbal persuasion & $-.82^{*}$ & .002 \\
\hline
\end{tabular}

Note. ${ }^{*} \mathrm{p}<.05$

\section{Research Question 2}

Another set of questions sought to measure how important the students thought of each efficacyshaping source in determining their decisions on groups' capability. Table 2 shows the results of their answers.

Table 2. Perception of Importance of Four Efficacy Shaping Sources in Determining Collective Efficacy

\begin{tabular}{lcc}
\hline Source & Mean & Standard Deviation \\
\hline Mastery experience & 5.36 & 1.27 \\
Verbal persuasion & 5.15 & 1.21 \\
Vicarious experience & 4.59 & 1.36 \\
Affective state & 4.49 & 1.38 \\
\hline
\end{tabular}

(From 1 - not important at all to 7- extremely important)

\begin{tabular}{llcc}
\hline Source & & Mean Difference & Significance \\
\hline Mastery experience & Vicarious experience & $.77^{*}$ & .002 \\
& Verbal persuasion & .20 & .782 \\
& Affective state & $.86^{*}$ & .001 \\
\hline Vicarious experience & Mastery experience & $-.77^{*}$ & .002 \\
& Verbal persuasion & $-.57^{*}$ & .046 \\
& Affective state & .09 & .974 \\
\hline Verbal persuasion & Mastery experience & -.20 & .782 \\
& Vicarious experience & $.57^{*}$ & .046 \\
& Affective state & $.66^{*}$ & .014 \\
\hline Affective state & Mastery experience & $-.86^{*}$ & .001 \\
& Vicarious experience & -.09 & .974 \\
& Verbal persuasion & $-.66^{*}$ & .014 \\
\hline
\end{tabular}

Note. ${ }^{*} \mathrm{p}<.05$

As shown in Table 2, mastery experience and verbal persuasion were the two sources that scored high; however, the mean difference between the two constructs was not statistically significant. In addition, the mean scores of both mastery experience and verbal persuasion were higher than those of other two constructs (i.e. vicarious experience and affective state), and the differences of the means were statistically significant. 


\section{Research Question 3}

It was also sought whether there were additional sources of efficacy shaping other than the four sources identified from the literature. Qualitative data from the interviews of 16 students who volunteered for the interview were also gathered to examine if there were any additional sources other than the four. Thus, the question was worded as "When you were asked to assess your group's capability, what kinds of things did you consider to form your decision?" without mentioning the four sources of efficacy shaping in an attempt to facilitate the use of their own words. 12 out of 16 interviewees answered the question regarding the source of efficacy shaping, and 9 out of the 12 answers were coded as mastery experience either directly or indirectly related to successful past group-work experience. The remaining three answers were coded as vicarious experience. Examples of answers coded as mastery experience are, “... I think the most important piece was that we had a reasonably good group...", "... we worked pretty well... yeah... we got what we needed to done", and "None of the group members worked, that never happened to me before." Examples of the answers related to vicarious experience are, "... I felt like we had some decent strong group members, that had good work ethics, some knows much..." and "... I like the problem solving stuff, and how they resolve difference issues, how they work, like their work ethic..." Thus, the results from the interviews were categorized by the four sources of efficacy shaping identified in the literature.

\section{Groups' Collective Efficacy and Leadership}

\section{Research Question 4}

In order to answer the question, "Are there any differences in the level of collective efficacy between groups with identified leader(s) and groups without identified leader(s)?" the groups with group-identified leader(s) were first identified. Because the students were asked to identify the person(s) who showed more leadership than others, members who received the most votes among all group members were identified as leader(s) of each group. If two of the members had the same vote, they were both identified as co-leaders of their group. In the same way, if 2 out of 3 members said they did not have a leader, the group was identified as a group without groupidentified leader(s). As a result, 19 out of 25 groups were identified to have leader(s), and the remaining 6 groups were considered to have no leader. To compare the means of the groups' collective efficacy for the two kinds of groups, an independent samples t-test was conducted. Table 3 shows the results of the t-test.

Table 3. Groups' Collective Efficacy between the Two Groups with and without Group-Identified Leader(s)

\begin{tabular}{lllll}
\hline & Groups with leader(s) & N & Mean & Std. Deviation \\
\hline Groups' & No & 16 & 3.8200 & 0.84656 \\
Collective Efficacy & Yes & 55 & 4.8147 & 0.81791 \\
\hline
\end{tabular}




\begin{tabular}{|c|c|c|c|c|c|c|}
\hline \multicolumn{7}{|c|}{ t-test for Equality of Means } \\
\hline \multirow[t]{2}{*}{$\mathrm{t}$} & \multirow[t]{2}{*}{$d f$} & \multirow[t]{2}{*}{ Sig. (2-tailed) } & \multirow[t]{2}{*}{$\begin{array}{l}\text { Mean } \\
\text { Difference }\end{array}$} & \multirow[t]{2}{*}{$\begin{array}{l}\text { Std. Error } \\
\text { Difference }\end{array}$} & \multicolumn{2}{|c|}{$\begin{array}{l}\text { 95\% Confidence } \\
\text { Interval of the } \\
\text { Difference }\end{array}$} \\
\hline & & & & & Lower & Upper \\
\hline-4.249 & 69 & $.000 * *$ & -.999473 & .23412 & -1.46178 & -.52768 \\
\hline
\end{tabular}

According to Table 3, the $p$ value was statistically significant at $\alpha=.001$ level. Thus, the mean of collective efficacy among the groups with identified leader(s) was significantly different from the mean for the groups without identified leader(s). The mean collective efficacy of the groups without leader(s) is 3.82, and that of the groups with leader(s) is 4.81 . The value from Levene's test for equality of variance was .923, which means that the difference between the variances of two groups is not statistically significant. Thus, the homogeneity of variance assumption was met for the analysis.

\section{Research Question 5}

In order to examine if there were any significant differences in the 10 leadership traits between the students who were identified as leader(s) and the students who were not, an independent samples t-test was also conducted. The results of the t-test showed that there were no leadership traits significantly different between the students identified as leader(s) and those who were not.

In addition to the survey, 16 one-on-one interviews were also conducted, and the interview data were transcribed, coded, and analyzed in order to examine if there were certain outstanding themes regarding the students' thoughts on what an ideal leader should look like. 15 out of 16 interviewees answered the question about what ideal leaders should do or look like. According to the coding result, a total of 6 themes emerged: time management, task management, social ability, individual responsibility, emotional support, and being a role model. To be more specific, time management involved leaders' behavior to make sure the outcome would be done on time, and task management referred to leaders' behavior to make sure that tasks would be done and to check that everyone was doing their job. Social ability entailed leaders' ability to communicate well and get along well with other members. Responsibility referred to leaders' individual sense of responsibility, and emotional support included encouraging other members to do a better job or motivating other members to complete their work. One student mentioned that ideal leaders should be persons that other students could look up to. Table 4 shows the result of analysis of the interview transcriptions. 
Table 4. Themes from the Students' Perception on What Ideal Leaders Should Do

\begin{tabular}{lc}
\hline Theme & Frequency of Emergence \\
\hline Task Management & 13 \\
Social ability & 5 \\
Emotional support & 3 \\
Task Management & 2 \\
Responsibility & 2 \\
Role model & 1 \\
\hline
\end{tabular}

From the analysis, task management was the theme that was mentioned most often in the interviews, followed by social ability. Examples of the task management theme included, "I think just keeping everybody on track, making sure that everybody is doing what they need to do, getting it done, and not being off task, like that's the main thing that the groups struggle with." Examples of the social ability theme included, "...get along with other group members, socialize well, and understand others well..."

\section{Research Question 6}

To answer the final research question, whether there is any correlation with the level of groups' collective efficacy and the performance outcome of the groups, a bivariate correlation analysis was conducted. Table 5 shows the results of the analysis.

Table 5. Correlation between Groups' Collective Efficacy and Performance Outcomes

\begin{tabular}{|c|c|c|c|}
\hline & & $\begin{array}{c}\text { Groups' } \\
\text { Collective efficacy }\end{array}$ & $\begin{array}{c}\text { Performance } \\
\text { outcomes (Final } \\
\text { grade) }\end{array}$ \\
\hline \multirow{3}{*}{$\begin{array}{l}\text { Group's collective } \\
\text { efficacy }\end{array}$} & Pearson Correlation & 1.00 & $.334^{* *}$ \\
\hline & Sig. (2-tailed) & & .004 \\
\hline & $\mathrm{N}$ & 76 & 73 \\
\hline \multirow{3}{*}{$\begin{array}{l}\text { Performance outcome } \\
\text { (Final grade) }\end{array}$} & Pearson Correlation & $.334 * *$ & 1.00 \\
\hline & Sig. (2-tailed) & .004 & \\
\hline & $\mathrm{N}$ & 73 & 73 \\
\hline
\end{tabular}

Note. ${ }^{* *} \mathrm{p}<.01$

The results showed that there was a positive correlation between the groups' collective efficacy and their performance outcomes, which were the grades given by the teachers. The correlation coefficient was $r=.334$, and was statistically significant at $\alpha=0.01$ level. 


\section{Types of Leadership Traits and Successful Group Work}

As the study mainly has an exploratory characteristic as well as confirmatory, further analysis of leadership traits was conducted to examine the relationship between types of leadership traits and students' success in group work. Given that most of the groups were identified to have leader(s), an effort was made to examine if there was any significant difference in the leadership traits between the identified leaders and the non-identified leaders. The results of the t-test showed there was no significant difference in the individual leadership traits between the leaders and the non-leaders. It was assumed that the relatively small number of the leaders $(N=16)$ might affect the result of the t-test that showed no statistically significant difference.

Although there were no differences in the 10 individual leadership traits between the identified leaders and the non-leaders, an exploratory factor analysis (EFA) was conducted to examine if the 10 leadership traits could be explained by any factors. Maximum likelihood extraction with promax rotation was performed through SPSS 18 on the 10 leadership traits with absence of multicollinearity. Two factors with an eigen value higher than 1 were extracted. With a cutoff of .40 for inclusion of a variable in interpretation of a factor, all of the variables loaded on either of the two factors.

The eigen value of Factor 1 was 4.439 and it included 5 traits: being perceptive, self-confident, self-assured, persistent, and determined. The eigen value of Factor 2 was 1.637 and it contained the remaining five traits: being articulate, trustworthy, dependable, friendly, and outgoing. The five traits explained by Factor 1 could be named as self-traits because they represented individual self-traits without involving interactions with others. The five traits explained by Factor 2 could be named as social-traits because they represented the traits necessarily involving interactions with others. With the two factors $60.76 \%$ of total variance is explained, and there are 18 nonredundant residuals with absolute values greater than 0.05 . Self-traits and social-traits correlated .562. Table 6 presents the pattern matrix.

Table 6. Pattern Matrix for Leadership Traits

\begin{tabular}{lclc}
\hline & \multicolumn{3}{c}{ Factor } \\
\cline { 2 - 4 } & Self-traits & & Social-traits \\
\hline Articulate & 0.26 & Articulate & 0.444 \\
\hline Perceptive & 0.519 & Perceptive & 0.198 \\
\hline Self-confident & 0.735 & Self-confident & -0.107 \\
\hline Self-assured & 0.854 & Self-assured & -0.183 \\
\hline Persistent & 0.746 & Persistent & -0.091 \\
\hline Determined & 0.767 & Determined & 0.083 \\
\hline Trustworthy & 0.19 & Trustworthy & 0.668 \\
\hline Dependable & 0.279 & Dependable & 0.648 \\
\hline Friendly & -0.358 & Friendly & 0.73 \\
\hline Outgoing & -0.073 & Outgoing & 0.614 \\
\hline
\end{tabular}

Note. Extraction Method: Maximum Likelihood. Rotation Method: Promax with Kaiser Normalization. Rotation converged in 3 iterations. 
Based on the two types of leadership traits obtained by EFA (i.e. self-traits and social-traits), a bivariate correlation analysis was conducted to examine if there was any correlation between the two types of leadership traits and individual collective efficacy. Since leadership traits are an individual construct, individual collective efficacy was used for analysis instead of group collective efficacy. Table 7 shows the result of the correlation analysis.

Table 7. Correlation between Types of Leadership Traits and Individual Collective Efficacy

\begin{tabular}{|c|c|c|c|c|}
\hline & & $\begin{array}{l}\text { Leadership } \\
\text { traits (Self) }\end{array}$ & $\begin{array}{l}\text { Leadership } \\
\text { traits (Social) }\end{array}$ & $\begin{array}{c}\text { Collective } \\
\text { efficacy }\end{array}$ \\
\hline \multirow{3}{*}{$\begin{array}{l}\text { Leadership traits } \\
\text { (Self) }\end{array}$} & Pearson Correlation & 1.00 & $.615^{* *}$ & .091 \\
\hline & Sig. (2-tailed) & & .000 & .469 \\
\hline & $\mathrm{N}$ & 66 & 66 & 66 \\
\hline \multirow{3}{*}{$\begin{array}{l}\text { Leadership traits } \\
\text { (Social) }\end{array}$} & Pearson Correlation & $.615^{* *}$ & 1.00 & $.276^{*}$ \\
\hline & Sig. (2-tailed) & .000 & & .025 \\
\hline & $\mathrm{N}$ & 66 & 66 & 66 \\
\hline \multirow[t]{3}{*}{ Collective efficacy } & Pearson Correlation & .091 & $.276^{*}$ & 1.00 \\
\hline & Sig. (2-tailed) & .469 & .025 & \\
\hline & $\mathrm{N}$ & 66 & 66 & 67 \\
\hline
\end{tabular}

Note. ${ }^{*} \mathrm{p}<.05,{ }^{* *} \mathrm{p}<.01$

The result from the correlation analysis showed that individual collective efficacy had a positive correlation with social leadership traits. The coefficient of correlation, $r$ is statistically significant at $\alpha=0.05$ level. That means that students who rated themselves as having higher social leadership traits also showed higher levels of individual collective efficacy in general. With this finding in correlation between individual social leadership traits and individual collective efficacy, another correlation analysis was conducted to examine if there was any correlation between the frequency of mastery experience and individual social leadership traits. Table 8 shows the result of the analysis.

It is important to note that both pre- and post-results of the frequency of mastery experience in group work had a positive correlation with individual social leadership traits. Therefore, individual social leadership traits were considered to have positive correlations with both frequency of successful group-work experience and level of collective efficacy. Thus, the higher a student's social leadership traits were, the more he or she experienced successful group work and the higher his or her collective efficacy level. 
Table 8. Relationship between the Frequency of Mastery Experience and Social Leadership Traits

\begin{tabular}{llcc}
\hline & & Social traits (Pre) & Social traits (Post) \\
\hline $\begin{array}{l}\text { Frequency of mastery } \\
\text { experience (Pre) }\end{array}$ & Pearson Correlation & $.247^{*}$ & $.243^{*}$ \\
\cline { 2 - 4 } & Sig. (2-tailed) & .040 & .063 \\
\cline { 2 - 4 } & $\mathrm{N}$ & 69 & 59 \\
\hline $\begin{array}{l}\text { Frequency of mastery } \\
\text { experience (Post) }\end{array}$ & Pearson Correlation & $.297^{*}$ & $.253^{*}$ \\
\cline { 2 - 4 } & Sig. (2-tailed) & .021 & .040 \\
\cline { 2 - 4 } & $\mathrm{N}$ & 60 & 66 \\
\hline
\end{tabular}

Note. ${ }^{*} \mathrm{p}<.05$

Even though individual social leadership traits showed a positive correlation with collective efficacy and with frequency of experiencing successful group work, the previous t-test on each leadership trait for the groups with identified leader(s) compared to those with non-identified leader(s) showed that there were no significantly different leadership traits between the two kinds of groups. Therefore, instead of t-test, the percentage of the students in a group with identified leader(s) and in a group with non-identified leader who rated themselves high (i.e. 6 or 7 out of 7 scales) was examined on each leadership trait to explore if there were any traits that showed a noticeable difference in percentages of high scorer. Table 9 shows the result.

Table 9. Percentage of Students Rated Either 6 or 7 for Each Leadership Trait

\begin{tabular}{lccccc}
\hline & Articulate & Perceptive & Self-confident & Self-assured & Persistent \\
\hline Identified leaders & $60.0 \%$ & $44.0 \%$ & $36.0 \%$ & $40.0 \%$ & $60.0 \%$ \\
\hline $\begin{array}{l}\text { Non-identified } \\
\text { leaders }\end{array}$ & $58.5 \%$ & $51.2 \%$ & $61.0 \%$ & $39.1 \%$ & $53.7 \%$ \\
\hline Difference & $1.5 \%$ & $-7.2 \%$ & $-25 \%$ & $0.9 \&$ & $6.3 \%$ \\
\hline & Determined & Trustworthy & Dependable & Friendly & Outgoing \\
\hline Identified leaders & $48.0 \%$ & $60.0 \%$ & $68.0 \%$ & $60.0 \%$ & $56.0 \%$ \\
\hline $\begin{array}{l}\text { Non-identified } \\
\text { leaders }\end{array}$ & $46.4 \%$ & $61.0 \%$ & $58.6 \%$ & $68.3 \%$ & $63.4 \%$ \\
\hline Difference & $1.6 \%$ & $-1.0 \%$ & $9.4 \%$ & $-8.3 \%$ & $-7.4 \%$ \\
\hline
\end{tabular}

Table 9 shows that being "dependable" and "persistent" were identified as having a higher percentage of the students who were identified as leaders (rated 6 or 7 for the traits) than students who were not identified as leader(s). The descriptions provided for the two traits are "I am dependable - consistent and reliable" and "I am persistent - stay fixed on the goal(s), despite interference", respectively. It is interesting to note that two of the most prominent traits of identified leaders are aligned with the interview data on what an ideal leader should look like. In the interview analysis, the prominent themes that emerged were task management and time management, and they could be combined into project management. Given the description of traits, being persistent (i.e. stay fixed on the goal(s) despite interference) especially seems to be 
related to project management. It also seems that project management was identified as the strongest trait expected from ideal leaders because the context was a project-based learning school classroom where the students were constantly exposed to multiple projects. To examine the relationship between the traits and the actual leadership behaviors beyond looking at identified leaders' traits could be valuable to identify which traits are related to which leadership behaviors in a project-based learning environment especially where there is no designated leader for group work. In addition despite the fact that the survey is based on self-response, it shows some potential to be used for grouping in a project-based learning context (e.g. distributing students who rated themselves high in items such as "being persistent" and "being dependable" to each group).

Lastly, in terms of the relationship between groups' collective efficacy and their performance outcomes, the results showed a positive correlation between the two, which was confirmatory with the previous studies (Goddard, 2001, 2003; Gully et al., 2002; Stajkovic et al., 2009). However, it is notable that the context was where the group work lasted generally four to five weeks and kept changing, whereas the contexts of previous studies on collective efficacy were mainly where teams or groups had been formed and maintained for longer periods of time.

\section{Discussion}

As found in Table 1 and Table 2, mastery experience and verbal persuasion were the two most prominent efficacy-shaping sources in terms of frequency and students' perceptions of importance. Even though the students answered that they had experienced verbal persuasion more frequently than mastery experience, they perceived the importance of mastery experience slightly higher than that of verbal persuasion. It can be understood that, since the context is group work in a project-based learning environment, the students had been interacting with other group members and teachers exchanging feedback, but the group work had not necessarily been successful. The students perceived that, even though they had not experienced successful group work as frequently as verbal persuasion, they thought that mastery experience played a more important role in determining their groups' capability in general, based on their past group-work experiences.

This finding is consistent with what Bandura (2000) and Goddard $(2001,2003)$ indicated in the literature, that mastery experience is the most powerful source of efficacy-shaping among the four sources: mastery experience, vicarious experience, verbal persuasion, and affective state. Goddard (2001) once identified in his study that mastery experience was an important way to build collective efficacy in schools. In his case, the subjects were teachers in the schools, and the collective entity was their school, where a majority of them had worked for years. It is important that the same result was obtained in this study in the context of group work where the project lasted 5 weeks and where the students form new groups for each project. Data from the interviews with 16 students confirmed that successful group work experience (i.e. mastery experience) was the most influential source of efficacy shaping. The interview data eventually showed that either successful or unsuccessful group work experience was most influential for them to determine their group's capability in general. 
In terms of the relationship between existence of leadership and groups' collective efficacy, from the t-test of collective efficacy between the groups with identified leader(s) and the groups without leader(s), it was noted that the mean difference between the two groups' collective efficacy was significantly different, and the collective efficacy of the groups with leader(s) was higher. Even though they did not have any leader(s) designated by the teachers or they likely informally selected a leader, it was found that the students from 19 groups out of 25 identified leader(s) in their groups after the project was over.

Thus, it can be summarized that groups with leaders are likely to have higher collective efficacy than that of groups without leaders, which may result in successful group work (i.e. higher performance). Successful group work experience can help individual students build higher collective efficacy belief in the group work, which subsequently may lead to better group performance in upcoming group works. Moreover, the result of exploratory analysis on leadership traits shed lights on ways to improve group performance in project-based learning. Instead of having no or random grouping strategies, teachers can utilize the results of student's self-report on individual leadership traits to distribute students with higher social leadership traits to each group. Those students may resume leader roles in groups, which can facilitate higher group performance outcomes.

Another implication that is pertinent to educational technology can be found from the unique context of the study. The school has a one-to-one student-computer ratio and every curriculum is based on project-based learning, and their group works at school center around computers. In general, research studies in educational technology tend to focus on technology itself. For example, examining effectiveness of new teaching and learning technologies can be one of the popular topics in educational technology research studies. However educational psychology elements are often overlooked even though it can play a significant role in promoting better outcomes in technology implementation. This study attempted to connect educational psychology element to educational technology context, and showed that collective efficacy and leadership traits can be utilized to promote better outcomes of students in a computer-mediated, projectbased learning group work context. It is noteworthy that more efforts to integrate educational psychology knowledge into educational technology studies are needed in order to facilitate better outcomes.

\section{Limitations and Future Research}

There are some limitations of the present study. The first limitation is the possibility that students' responses for their general collective efficacy could have been influenced by their latest groupwork experience. For example, in the pre-survey, they were asked to rate their general level of collective efficacy from their past group-work experiences; however, they may have only looked back on their most recent group work to answer the question. Another limitation of this study is the validity of the students' answers. Because the survey was based on self-assessment, there are some doubts about the validity of the students' answers because they were not triangulated with other methods of data collection such as observation or teacher assessment. 
For the future research, it appears to be beneficial to examine what affects successful group experience, and to examine the relationship between certain leadership traits and behaviors. In addition, along with collective efficacy, it can be helpful to investigate the relationship between collective efficacy and individual self-efficacy as well as groups' self-regulation.

\section{References}

Bandura, A. (1977). Self-efficacy: Toward a unifying theory of behavioral change. Psychological Review, 84, 191-215. doi: 10.1037/0033-295X.84.2.191

Bandura, A. (1978). Self-efficacy: Toward a unifying theory of behavioral change. Advances in Behaviour Research and Therapy, 1(4), 139-161. doi: Doi: 10.1016/0146-6402(78)90002-4

Bandura, A. (1986). Social foundations of thought and action: A social cognitive theory. Englewood Cliffs, NJ: Prentice Hall.

Bandura, A. (2000). Exercise of human agency through collective efficacy. Current Directions in Psychological Science, 9(3), 75-78.

Bandura, A. (2006). Guide for constructing self-efficacy scales. In F. Pajares \& T. Urdan (Eds.), Adolescence and education: Vol. 5. Self-efficacy beliefs of adolescents (pp. 307-337). Greenwich, CT: Information Age.

Bass, B.M. (1990). From Transactional to Transformational Leadership: Learning to Share the Vision. Organizational Dynamics, 18(3), 19-31.

Burns, J. M. (1978). Leadership. New York: Harper \& Raw.

Chen, G. \& Bliese, P.D. (2002). The role of different levels of leadership in predicting self- and collective efficacy: Evidence for discontinuity. Journal of Applied Psychology, 87(3), 549-556. doi: 10.1037//0021-9010.87.3.549

George, T. R. \& Feltz, D. L. (1995). Motivation in sport from a collective efficacy perspective. International Journal of Sport Psychology, 26(1), 98-116.

Gibson, C. B. (1999). Do they do what they believe they can? Group efficacy and group effectiveness across tasks and cultures. Academy of Management Journal, 42, 138-152.

Gibson, C. B., Randel, A., \& Earley, P. C. . (2000). Understanding group efficacy: An empirical test of multiple assessment methods. Group \& Organization Management, 25, 67-97.

Goddard, R.D. (2001). Collective efficacy: A neglected construct in the study of schools and student achievement. Journal of Educational Psychology, 93(3), 467-476. doi: 10.1037//00220663.93.3.467

Goddard, R.D. (2003). The impact of schools on teacher beliefs, influence, and student achievement: The role of collective efficacy. In J. Raths \& A. McAninch (Eds.), Advances in teacher education (Vol. 6, pp. 183-204). Westport, CT: Information Age Publishing.

Goddard, R.D., Hoy, W.K., \& Hoy, A.K. (2004). Collective efficacy beliefs: Theoretical developments, empirical evidence, and future directions. Educational Researcher, 33(3), 3-13. doi: 10.3102/0013189X033003003 
Groves, R. M., Fowler, F. J., Couper, M. P., Lepkowski, J. M., Singer, E., \& Tourangeau, R. (2009). Survey methodology. New York: John Wiley \& Sons.

Gully, S.M., Incalcaterra, K.A., Joshi, A., \& Beaubien, J.M. (2002). A meta-analysis of team-efficacy, potency, and performance: Interdependence and level of analysis as moderators of observed relationships. Journal of Applied Psychology, 87(5), 819-832. doi: 10.1037/00219010.87.5.819

Hoyt, C.L., Murphy, S.E., Halverson, S.K., \& Watson, C.B. (2003). Group Leadership: Efficacy and Effectiveness. Group Dynamics: Theory, Research, and Practice, 7(4), 259-274. doi: 10.1037/1089-2699.7.4.259

Jex, S. M. \& Gudanowski, D. M. (1992). Efficacy beliefs and work stress: An exploratory study. Journal of Organizational Behavior, 13(5), 509-517.

Kirkpatrick, S. A. \& Locke, E. A. (1991). Leadership: Do traits matter? The Executive, 5, 48-60.

Lincoln, Y. S. \& Guba, E. G. (1985). Naturalistic inquiry. Thousands Oaks, CA: Sage.

Lindsley, D. H., Brass, D. J., \& Thomas, J. B. (1995). Efficacy-performance spirals: A multilevel perspective. Academy of management Review, 20(3), 645-678.

Northouse, P. (2004). Leadership: Theory and practice. . Thousand Oaks, CA: Sage Publications.

Parker, L. E. (1994). Working Together: Perceived Self- and Collective-Efficacy at the Workplace1. Journal of Applied Social Psychology, 24(1), 43-59. doi: 10.1111/j.1559-1816.1994.tb00552.x

Partnership for 21st Century Skills (2010). Framework for 21st century learning. http://www.p21.org/index.php?option=com_content\&task=view\&id=254\&Itemid=120

Reigeluth, C.M., Watson, W.R., Watson, S.L., Dutta, P., Chen, Z., \& Powell, N.D.P. (2008). Roles for technology in the information-age paradigm of education: Learning management systems. Educational Technology, 48(6), 32-39. http://jaems.jp/contents/news/130_LMS.pdf

Riggs, M. L. \& Knight, P. A. (1994). The impact of perceived group success-failure on motivational beliefs and attitudes: A causal model. Journal of Applied Psychology, 79(5), 755-766.

Riggs, M. L., Warka, J., Babasa, B., Betancourt, R., \& Hooker, S. (1994). Development and Validation of Self-Efficacy and Outcome Expectancy Scales for Job-Related Applications. Educational and Psychological Measurement, 54(3), 793-802. doi: 10.1177/0013164494054003026

Stajkovic, A.D., Lee, D., \& Nyberg, A.J. (2009). Collective efficacy, group potency, and group performance: Meta-analyses of their relationships, and test of a mediation model. Journal of Applied Psychology, 94(3), 814-828. doi: 10.1037/a0015659

Stogdill, R. M. (1948). Personal factors associated with leadership: A survey of the literature. Journal of Psychology, 25, 35-71.

Stogdill, R. M. (1974). Handbook of leadership: A survey of theory and research. New York: Free Press.

Walumbwa, F.O., Wang, P., Lawler, J.J., \& Shi, K. (2004). The role of collective efficacy in the relations between transformational leadership and work outcomes. Journal of Occupational and Organizational Psychology, 77, 515-530. 
Wood, R. \& Bandura, A. (1989). Social cognitive theory of organizational management. Academy of management Review, 14(3), 361-384.

Zaccaro, S. J., Blair, U., Peterson, C., \& Zazanis, M. (1995). Collective efficacy. New York: Plenum.

Correspondence: Yeol Huh, Instructor, Department of Instructional Systems Technology, School of Education, Indiana University, Bloomington, Indiana, United States 